\title{
Institutions and culture: The story of the EU and the fate of Europe's integration project
}

\begin{abstract}
'The great European dream was to diminish militant nationalism' (Antony Beevor). The future remains open, and some degree of nationalism may be constantly present, but one thing can be expressed with confidence: the European Union has successfully averted conflict within the 'club' and has been a clearly powerful incentive for reconciliation between former enemies as well as bringing democracy in countries formerly ruled by dictatorships. The present crisis apart, the European project remains incomparable. Indeed, this presents an inescapable imperative to any notion of resistance towards the completion of the European integration project. This article focuses on the integration project of the Old Continent's southeastern corner; more specifically, it concerns how a culture-based or incited-conflict can shape a specific cultural setting and, in return, how that culture can be transformed into one of co-operation. The inquiry is placed in the context of the relationship with, and impact of, the EU, which can serve both as example and promoter of such a culture.
\end{abstract}

Keywords: cross-cultural communication, EU, economic activity, public debt, labour markets, social welfare, competitiveness, training programmes, income inequality, corruption, rule of law, organised crime, reconciliation, co-operation, stability

\section{The relevant context}

A stable political climate, including a functioning institutional system and a state of effective rule of law, a constantly increased social welfare net and a strong or sustainable economy appear to be of decisive value for improving and consolidating crosscultural communication and interaction. The ultimate observation appears to be that the cultural consequences of a state of war can be rectified through a long-term process that requires constant improvements in each and every society.

Notable improvements have been achieved in regional relations between the southeast European nations, as one can observe through the EU-facilitated dialogue between Kosovo and Serbia, and the much-needed improvement in Bosnia and Herzegovina. The EU's role in solving the border disputes between Slovenia and Croatia, including the latter's recent accession into the EU, is an exemplar of the role the EU can play in the region.

With regard to Kosovo-Serbia relations, the current state of affairs presents an obvious and significant change when compared to a state of conflict and a total absence of official communications, not to speak of any high-level official meeting or of any 
such cardinal improvement as agreement on the normalisation of relations between the two countries. A bona fide and scrupulous implementation of the agreement is similarly critical. Yet the broader relationship is often exposed to tension, prejudice and the absence of any meaningful degree of genuine co-operation and interaction. Similarly, the persisting problem over the name of the country between Macedonia and Greece, the latter an EU member state and the former a candidate, signifies that existing improvements may only be partial.

The poor shape of the economy and an overall poor state of social welfare, coupled with slow processes of institutional consolidation and European integration, have delayed the prospects for consolidating the spheres of culture, communications and increased cross-cultural activity of all kinds in the region of south-east Europe. Therefore, interaction or communication is a necessary minimum to bridge the gap of inter-cultural silence and isolation. What boosts or confines such communication is of utmost relevance for transcending the minimum requirement.

\section{Economic activity}

The main measure of economic development is GDP growth, especially relative to the EU-27 if we are considering the issue of economic convergence. It is an important message that, despite the region's economic and political instability in the first half of the decade and the effects of the 2008-2010 economic crises, all countries have managed a significant level of catch-up. Serbia, Albania and Montenegro have achieved the most dynamic growth, nearly doubling their GDP per capita. Croatia moved almost in parallel with Poland, although starting at a somewhat higher level in 2000 and ending up slightly lower (but Poland has been the only country in the EU not to fall into recession during the crisis).

There is positive indication of economic convergence (Galgóczi and Sergi, 2012), and Table 1 shows domestic economic developments, using real growth rates for industrial production. Economic growth was highest in Albania and lowest in FYR Macedonia. In correspondence with convergence, all countries outpaced the EU-27, with the exception of Croatia and FYR Macedonia. The growth of industrial production was especially high in Albania and Bosnia and Herzegovina (both outpacing Poland), but was rather moderate in Serbia in 2010 and 2011, negative in Croatia (since 2009) and FYR Macedonia in 2009 and 2010. Montenegro, on the other hand, suffered a contraction of industrial activity during the decade (a 17.5 per cent increase in 2010 doing something to correct this), even though it managed significant growth in the economy as a whole. 
Table 1 - Annual growth rates for industry

\begin{tabular}{|l|c|c|c|c|}
\hline Country & $\mathbf{2 0 0 8}$ & $\mathbf{2 0 0 9}$ & $\mathbf{2 0 1 0}$ & $\mathbf{2 0 1 1}$ \\
\hline Albania & $8.7 \%$ & $10.6 \%$ & $18.6 \%$ & $10.0 \%$ \\
\hline Bosnia and Herzegovina & $7.3 \%$ & $1.5 \%$ & $3.7 \%$ & $5.6 \%$ \\
\hline Croatia & $1.2 \%$ & $-9.2 \%$ & $-1.4 \%$ & $-1.2 \%$ \\
\hline FYR Macedonia & $5.1 \%$ & $-8.7 \%$ & $-4.8 \%$ & $3.3 \%$ \\
\hline Montenegro & $-2.0 \%$ & $-32.2 \%$ & $17.5 \%$ & $-10.3 \%$ \\
\hline Serbia & $1.4 \%$ & $-12.6 \%$ & $2.5 \%$ & $2.1 \%$ \\
\hline & & & & \\
\hline Germany (a) & $-0.1 \%$ & $-16.3 \%$ & $10.9 \%$ & $7.6 \%$ \\
\hline Greece (a) & $-4.2 \%$ & $-9.2 \%$ & $-6.6 \%$ & $-8.1 \%$ \\
\hline Poland (a) & $2.4 \%$ & $-3.7 \%$ & $10.8 \%$ & $7.2 \%$ \\
\hline EU-27 (a) & $-1.8 \%$ & $-13.7 \%$ & $6.8 \%$ & $3.2 \%$ \\
\hline
\end{tabular}

Sources: Vienna Institute for International Economic Studies (2011); (a) Eurostat (excluding construction).

Public debt, which is at the epicentre of the second wave of the economic crisis in Europe, has remained at relatively low levels in south-east Europe (Table 2). Debt ratios are all below or on the recommended Maastricht criterion of 60 per cent, ranging from 27.7 per cent of GDP in FYR Macedonia to 39 per cent in Bosnia and Herzegovina, 46 per cent in Croatia and Montenegro, 49 per cent in Serbia and 60 per cent in Albania (the highest in the region) (IMF, 2011). If we compare gross external debt as a percentage of GDP in Bosnia and Herzegovina, Montenegro and Albania, it looks less vulnerable with a ratio of 26.1 per cent, 32.9 per cent and 49.5 per cent respectively. In contrast, gross external debt in Macedonia, Serbia and Croatia is thorny at 64.4 per cent, 79.5 per cent and 103.1 per cent respectively (although in Croatia and Serbia it consists of long-term debt which constitutes 85 per cent and 95 per cent of the total respectively, thereby plummeting the immediate roll-over risk). 
Table 2 - Fiscal balance and public debt, 2011

\begin{tabular}{|l|c|c|}
\hline Country & Fiscal balance, as \% of GDP & Public debt, as \% of GDP \\
\hline Albania & $-3.6 \%$ & $60.0 \%$ \\
\hline Bosnia and Herzegovina & $-1.3 \%$ & $39.0 \%$ \\
\hline Croatia & $-5.0 \%$ & $46.0 \%$ \\
\hline FYR Macedonia & $-2.5 \%$ & $27.7 \%$ \\
\hline Montenegro & $-4.1 \%$ & $45.9 \%$ \\
\hline Serbia & $-5.0 \%$ & $49.0 \%$ \\
\hline & & $80.5 \%$ \\
\hline Germany & $-0.8 \%$ & $170.6 \%$ \\
\hline Greece & $-9.4 \%$ & $56.4 \%$ \\
\hline Poland & $-5.0 \%$ & $82.5 \%$ \\
\hline EU-27 & $-4.4 \%$ & \\
\hline
\end{tabular}

Sources: Eurostat; Vienna Institute for International Economic Studies.

Regarding external economic balance, the current account position of south-east Europe countries shows high levels of deficit, especially in the pre-crisis boom period, as indicated in Table 3. This makes them similar to the Baltic States, which suffered most during the crisis in Europe and, generally, indicate a lack of competitiveness. The situation is particularly alarming in Montenegro, where the balance of payments deficit reached 40 per cent of GDP at the peak of the economic boom and, even in 2010, remained at dangerous levels. The high foreign investment levels for Montenegro in the past decade and the contraction of industrial activity, taken together, clearly indicate that the country is experiencing an unsustainable investment bubble. Albania shows persistently high levels of external deficit, but these do seem to be more manageable. Other countries seem to have corrected previously high current account deficits. 
Table 3 - Current account balance, as per cent of GDP

\begin{tabular}{|l|r|r|r|r|c|}
\hline Country & $\mathbf{2 0 0 4}$ & $\mathbf{2 0 0 5}$ & $\mathbf{2 0 0 7}$ & $\mathbf{2 0 1 0}$ & $\mathbf{2 0 1 1}$ \\
\hline Albania & -4.0 & -6.1 & -10.4 & -11.4 & -12.3 \\
\hline Bosnia and Herzegovina & -16.2 & -17.1 & -10.7 & -5.7 & -8.8 \\
\hline Croatia & -4.1 & -5.3 & -7.3 & -1.1 & -1.0 \\
\hline Kosovo & -8.4 & -7.4 & -8.3 & -17.4 & -20.3 \\
\hline FYR Macedonia & -8.1 & -2.5 & -7.1 & -2.1 & -2.7 \\
\hline Montenegro & -7.2 & -16.6 & -39.5 & -24.6 & -19.5 \\
\hline Serbia & -12.2 & -8.8 & -16.1 & -7.4 & -9.5 \\
\hline & & & & & \\
\hline Germany & 4.7 & 5.1 & 7.4 & 6.0 & 5.7 \\
\hline Greece & -5.8 & -7.6 & -14.6 & -10.1 & -9.8 \\
\hline Poland & -5.2 & -2.4 & -6.2 & -4.7 & -4.3 \\
\hline EU-27 & 0.5 & 0.1 & -0.4 & 0 & 0.2 \\
\hline
\end{tabular}

Source: IMF - World Economic Outlook Database (2012b).

\section{Labour market and social developments}

Whereas most economic indicators pertaining to south-east European countries do not seem shocking to the average European observer, the labour market is different. This is the reality, however. For some countries, labour market indicators are somewhat less shocking, although employment rates are generally significantly lower than in the EU. Employment rates are particularly low in Bosnia and Herzegovina and FYR Macedonia, but even that of Croatia, the best performer, is lower than the lowest value in the EU. Unemployment rates in the region are significantly higher than the EU-27 average, as Table 4 shows. With the exception of Croatia and Albania (13.5 per cent and 14 per cent, respectively), Bosnia and Herzegovina (27.6 per cent), FYR Macedonia (31.4 per cent) and Serbia (23 per cent) show particularly high values. Neither do the trends of the past four years indicate any consistent improvement, except in Albania (a slight increase from 13 to 14 per cent) and Macedonia (a shrinkage of 2.4 percentage points). All this happened at a time when the region achieved significant economic growth and a degree of catching-up with the more developed parts of Europe.

The phenomenon of rising unemployment and jobless growth have often been mentioned in the European context, particularly for central and eastern Europe, but the negative champion in this field is, without doubt, south-east Europe. Concerning the Eurozone, the number of unemployed people might rise to twenty million in 2013. This would be a historical record, well above the total number of unemployed in 2012 of 18.7 million, the highest level reached after the launch of the euro, while in 201015.9 million citizens of the Eurozone were without work. Concerning the western Balkans, 
even if signs of normalisation are clearly discernible in the economy as a whole, this is unfortunately not true of the labour market. Active labour market policies, e.g. vocational training and educational programmes for workers, are needed. If policy reforms were essential to restore competitiveness, boost job creation and make it more inclusive, this would impose a burden of wide-ranging social consequences. Extensive consultations between the social partners are crucial to maintaining social cohesion while restoring overall competitiveness and engineering a successful and lasting economic recovery.

Table 4 - Unemployment rate, LFS, (\%)

\begin{tabular}{|l|c|c|c|}
\hline Country & $\begin{array}{c}\text { Unemployment } \\
\text { rate, 2008 }\end{array}$ & $\begin{array}{c}\text { Unemployment } \\
\text { rate, 2010 }\end{array}$ & $\begin{array}{c}\text { Unemployment } \\
\text { rate, 2011 }\end{array}$ \\
\hline Albania & 13.0 & 13.7 & 14.0 \\
\hline Bosnia and Herzegovina & 23.4 & 27.2 & 27.6 \\
\hline Croatia & 8.4 & 11.8 & 13.5 \\
\hline FYR Macedonia & 33.8 & 32.0 & 31.4 \\
\hline Montenegro & 17.2 & 19.6 & 19.7 \\
\hline Serbia & 13.6 & 19.2 & 23.0 \\
\hline & & & \\
\hline Germany & 7.5 & 7.1 & 5.9 \\
\hline Greece & 7.7 & 12.6 & 17.7 \\
\hline Poland & 7.1 & 9.6 & 9.7 \\
\hline EU-27 & 7.1 & 9.7 & 9.7 \\
\hline
\end{tabular}

Sources: wiiw (2011) Handbook of Statistics 2011: Central, East and Southeast Europe Vienna Institute for International Economic Studies, Vienna; Eurostat.

Our data speak not only of an already high existing level of unemployment in the western Balkans region but, in many cases, also of an increased level in the aftermath of the global economic crisis. Unemployment rates in the region have increased by about two percentage points. In EU countries, this increase was about 2.4 points (Balaj, 2010: 41). Yet, the difference remains easily discernible, with unemployment rates in the region being significantly higher than the EU-27 average (Galgóczi and Sergi, 2012). Despite sustained economic growth and stability in south-east Europe, labour markets have not shown any significant scale of improvement.

Indeed, the effects of the global economic crisis are clearly involved in this equation. Richard Dobbs and Anu Madgavkar, researchers at McKinsey, authored a survey on 'Why the jobs problem is not going away' (in 2012) and offered an analysis of the 'mismatch' between the demand for and supply of graduates that will expand even further by 2020. In the advanced economies, it could fail to respond as regards a total of 16 to 18 million graduates, i.e. a supply 11 per cent less than demand, with potentially 
damaging consequences for GDP growth. The mismatch between the demand for and supply of highly-qualified professionals is a major problem and overcoming it is essential for growth.

The competitiveness of the western Balkans also relates to people's skills, quality, innovation and the existence of a national (and regional) system capable of enhancing these ideas. It is essential that young people be placed in conditions in which they can choose training in line with business requirements. Not surprisingly, companies have increased their focus on the issue of the quality of human resources, focusing even more on excellence in regional and international competition. However, apart from in a few cases, the region has a very traditional model of development, with little technology; well-prepared graduates emigrate to find good job opportunities.

If, on the other hand, we look at wage developments in the region, we again see signs of consolidation. Wage dynamics - for those who are in work - seem to be impressive (Table 5). Serbia and Montenegro, which also had a comparably more balanced labour market, take the lead, with real wage increases of 145 per cent (Serbia) and 95 per cent (Montenegro), respectively. Among those south-east European countries for which data were available, only Croatia had a lower real wage increase than the EU-27 average over the course of the decade, but Croatia also has an outstandingly high wage level for the region.

Table 5 - Monthly remuneration per employee, 2010

\begin{tabular}{|l|c|c|c|}
\hline Country & Euros & \% (EU-27=100) & $\begin{array}{c}\text { Index of real } \\
\text { wages, 2009 } \\
(\mathbf{2 0 0 0}=\mathbf{1 0 0})\end{array}$ \\
\hline Albania & 246 & 8.9 & $\mathrm{n} / \mathrm{a}$ \\
\hline Bosnia and Herzegovina & 622 & 22.4 & $\mathrm{n} / \mathrm{a}$ \\
\hline Croatia & 1054 & 38.0 & 121 \\
\hline FYR Macedonia & 491 & 17.7 & 159 \\
\hline Montenegro & 715 & 25.8 & 195 \\
\hline Serbia & 461 & 16.6 & 245 \\
\hline Poland & 883 & 31.8 & 125 \\
\hline EU-27 & 2776 & 100 & 134 \\
\hline
\end{tabular}

Note: Data for south-east Europe refer to average gross monthly wages.

Source: Vienna Institute for International Economic Studies (2011).

The Gini index measures the extent to which the distribution of income among individuals or households deviates from a perfectly equal distribution. A Gini index of zero represents perfect equality - everyone has the same income - while an index of one (100 on the percentile scale) implies perfect inequality in the income distribution (one person has all the country's income; everyone else has nothing). Growing income inequality is a general trend in Europe and there is no evidence to support the assump- 
tion of an equality-efficiency trade-off. Depressing wages has led to a loss of efficiency, with the purchasing power of the population being maintained through credit that has eventually built to unsustainable trends and concluded in a debt crisis (Galgóczi, 2011).

In south-east Europe, gross national savings tend to be quite low; except for Macedonia (23.4 per cent in 2011), the figures in the western Balkans are well below the savings ratios in Germany, Bulgaria, Slovenia and Poland (Albania's savings ratio, in particular, plummeted from 22.3 per cent in 2004 to 12.7 per cent in 2011) (Figure 1). This was not the case in all western Balkan countries, but the tendency to find a tradeoff between equality and efficiency is misleading when applied to the complexity of the region. The risk of growing income inequality can lead to social, economic and efficiency damage, while losing the positive external effects for society of having greater equality. The value of statistical income inequality data for countries with extreme labour market conditions may be questioned but, nevertheless, Figure 2 here provides an overview for the position in 2008. Surprisingly (or not), south-east European countries fare rather well while, in European comparison, FYR Macedonia is the only significant outlier. Serbia and Montenegro, on the other hand, have better results than Germany or the EU-27 average, at least as far as the formal economy is concerned.

\section{Figure 1 - Gross national savings (\% of GDP)}

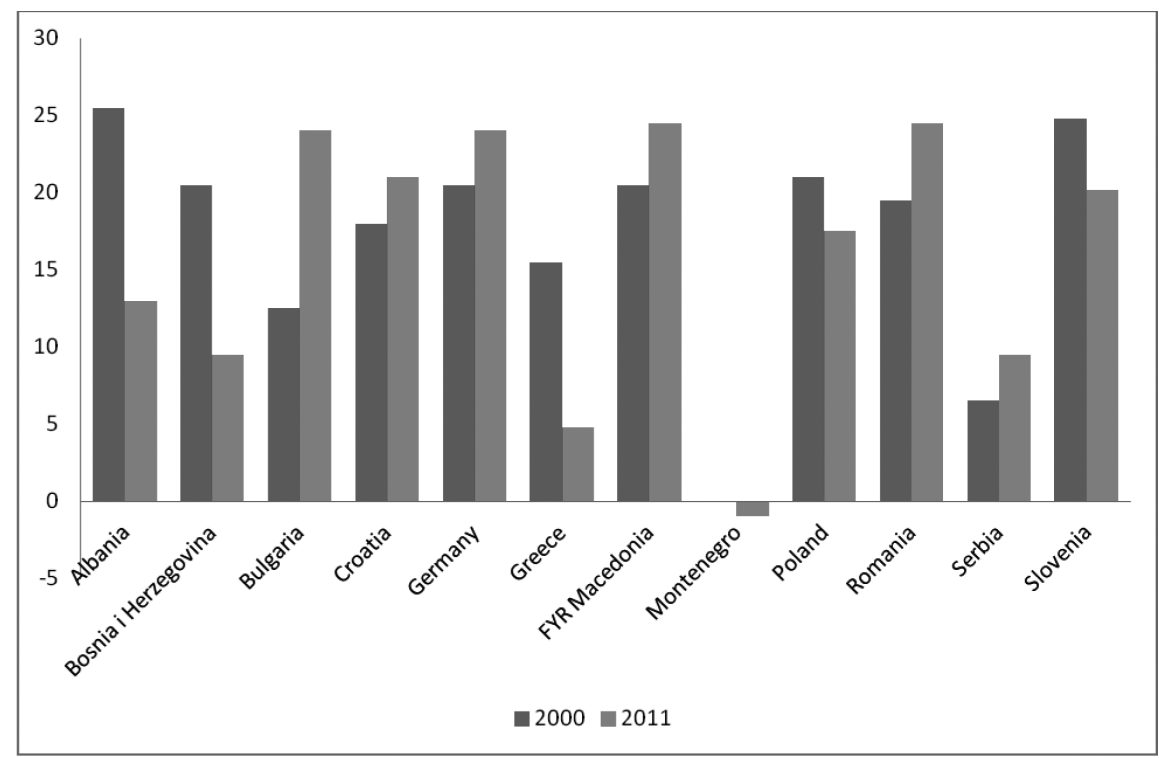


Figure 2 - Income inequality: the Gini index, 2008

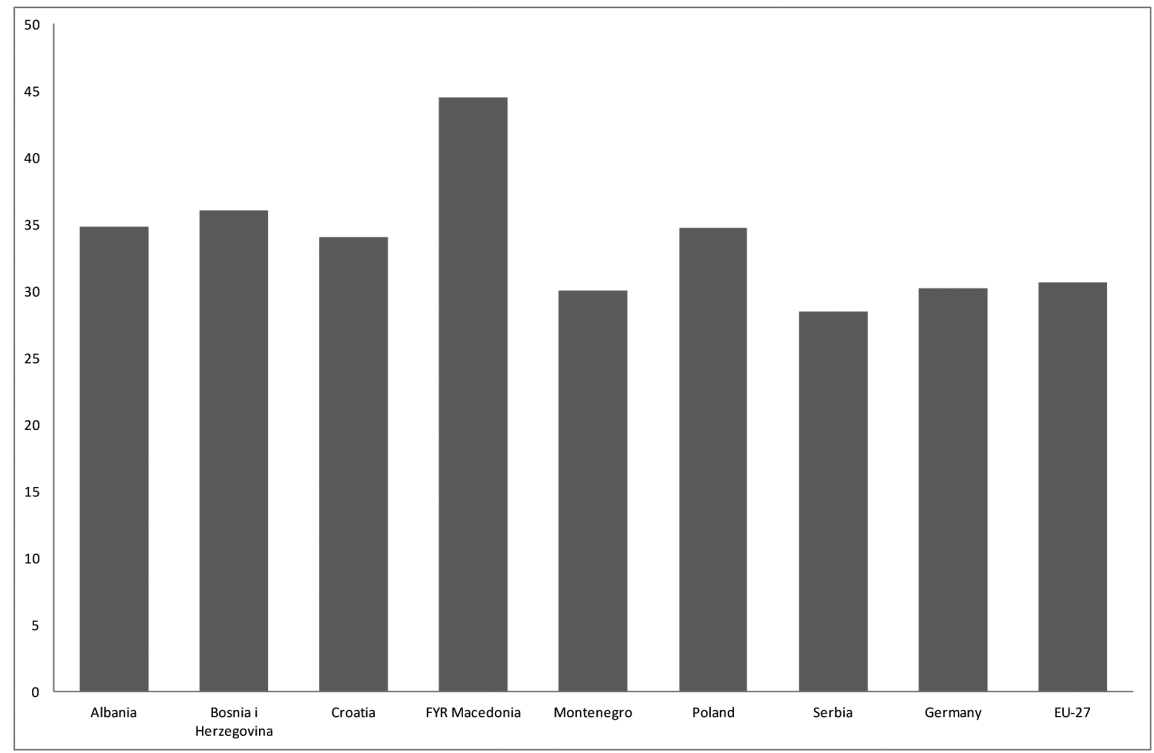

Note: Bosnia and Herzegovina data is for 2006.

Sources: World Bank; for Germany (DE) and EU-27: Eurostat.

The observed statistics, showing significantly high values for unemployment, indicate that social welfare is, overall, in a poor state, in particular among the countries of the narrowly-defined western Balkans, and one that is also poorly situated to boost positive cross-cultural communication and interaction in any clear or meaningful way (Qerimi and Sergi, 2012).

\section{Growth and good governance}

Another critical factor in the gamut of variables that could influence the outcome of cultural behaviour is the state of the economy. Indeed, as far as this aspect goes, as measured by GDP growth, paths of appreciable economic growth could be found during the past decade everywhere across the Balkan peninsula.

Notwithstanding the relative results in terms of increase in GDP, excluding the presumably temporary effects of the global economic downturn, the region is suffering from a number of phenomena that prevent it from growing into a strong and stable economic arena and, hence, one that is conducive to a flourishing environment for stable cross-cultural interaction.

One of the region's persisting challenges is a strengthening of the rule of law, in particular among those institutions that are empowered to enforce the law (Qerimi and Sergi, 2009; Sergi and Qerimi, 2006, 2007 and 2008). The problem of corruption has been one of the most enduring dilemmas confronting governments throughout history 
and it remains nowadays as one of the most serious problems in the Balkans, along with organised crime. High values of corruptive behaviour testify to the difficult path of reforming the institutional structure and strengthening the rule of law. It has been widely noted that economic activity in the region is often associated with, among other things, smuggling, extortion and tax evasion (Meyer and Nash, 2002). Such factors have a considerable impact on the region's governments in their efforts to develop and stabilise their economies and collect revenue. This is certainly a major obstacle to attracting foreign investment. Establishing the rule of law is, therefore, of paramount importance. The notion of the rule of law should be reflective of its key elements. It should, in particular, involve the indispensable notions of any institutional reform process, namely independence, accountability, representativeness, openness, oversight, gender sensitivity and access to justice (Ndulo and Duthie, 2009). Certainly, interests are better served by open and transparent competition.

The major thrust of the efforts of south-east European governments will have to be towards addressing the problems of corruption and ineffective rule of law, both as a matter of policy and as a part of their broader programmes on governance and capacity building. And there are some priority areas on which governments may concentrate their broader efforts. These include policy dialogue directed towards economic liberalisation and public administration reform; the liberalisation of licensing regimes; the opening up of access to foreign exchange markets; the reduction of administered prices; the removal of subsidies and soft loans to favoured companies; and the introduction of a clear distinction between production and regulatory functions. These are all policy changes that can level the playing field as well as reduce opportunities for corrupt or illicit behaviour.

Moreover, reconciliation is something that must be understood as a means of enhancing cross-cultural communication and co-operation. An important new result is that living in a bad neighbourhood, with undemocratic neighbours or, even worse, neighbours at war, significantly increases a country's risk of experiencing ethnic civil war. The obvious imperative is that ethnic conflict ought to be transcended; the paradigm of 'ethnicity' must be consciously shifted in a way that honours everyone's history, even though the histories may quite often be completely at odds with each other (Qerimi and Sergi, 2005).

\section{Reconciliation}

In post-conflict societies such as those in the western Balkans, a crucial element towards an increased level of cross-cultural communication and interaction is the reconciliation process. Sometimes, and at least theoretically, it may be impossible for some levels of conflict to be reconciled since the parties can get stuck trying to re-interpret each other's history or can get involved in debating certain controversial moments of the past. Thus, the consensus position may be that the parties agree not to discuss certain hurtful parts of their history, at least not until they can resolve their present difficulties and establish a level of trust. However, the ways and means of establishing a new interethnic dialogue should be considered in order to create a new atmosphere in relations between the members of different communities, both as a contribution to, and a prerequisite for, a peaceful future for all communities, wherever they are. 
An essential factor in this whole process, however, remains economic and social stability, which can also play a crucial role in increasing the prospects for reconciliation. The critical factors are the strengthening of economic stability and the improvement of the means of communication. This is both for economic reasons and development from which, afterwards, regional societies may intensify their contacts, as well as to deepen the understanding and acknowledgement of one another through academic, cultural and youth exchanges (Qerimi and Sergi, 2005, 2009 and 2012).

\section{Conclusion}

Ultimately, any effort to achieve genuine improvement in cross-cultural interaction requires solid regional co-operation and socio-economic stability. Such regional cooperation would scarcely be met without other complementary variables. The major concerns of the regional reform process remain corruption, organised crime and reconciliation. It is time that countries of the region acted upon a belief that peaceful coexistence is the key to political and economic stability, which is also a key requirement of the EU, the club to aspire to for all existing non-members, where membership commits all states to openness and tolerance vis-à-vis each other. Economic and social stability is a driving force behind the processes of cross-cultural communication and co-operation. Education reform definitely holds another key to the process. NGOs and media reform could further enhance any reconciliation endeavour. The main purpose here is to interpret the way in which the 'EU factor' (Sergi, 2004) may partially be associated with missed opportunity in the past, but also with the likelihood of such countries in the future becoming more stable and attractive areas for more multinationals.

South-east European countries have been very diverse over the past decade and this has been reflected in their economic growth rates. So-called 'latecomers' - following the example of those countries that experienced economic growth and foreign investment earlier - need to strengthen their competitiveness through a system which is much more oriented towards pro-business requirements. If there are grounds for foreign capital inflows to be released by the last 'round' of privatisation, the region calls for much greater efforts designed towards constructive end results. The underlying purpose remains that of becoming aware of the 'EU factor', greater regional co-operation in the advancement of industry clusters and various incentives - all these factors being of equal worth to foreign investors.

Progressive and innovative policies which are oriented towards business should be designed to produce an economic environment in the south-east Europe region which can respond successfully to rapid changes in an ultra-competitive business situation, both regionally and internationally. To that end, and in keeping with the evolving European and international conditions, industrial policies must be structured in such a way as to provide the highest degree of flexibility and responsiveness for entrepreneurs.

This setting, of necessity, encompasses many important aspects. Industrial policy is included in the stability and attractiveness requirements for becoming a region of economic success, making the most of the very interesting geographical position that south-east Europe enjoys and construing a productive platform for goods and services to be exported to west and to east. 
Ultimately, the cultural consequences of war can indeed be corrected only through a longer-term process based on addressing continuing improvements in the internal social settings of each and every society affected. Only improvements focused on facilitating individual and collective access to all the values that are universally desired can lead to genuine improvements in the state of inter-cultural relations in the region. An institutional setting, which is accountable and responsive to human needs and aspirations, can be decisive for improved inter-cultural relations. The EU has, so far, shown that it is capable of enhancing to a necessary degree the process of transformation from conflict to co-operation and inter-cultural interaction.

\section{References}

Balaj, B (2010) 'The Impact of the Global Economic Crisis' in J. Bugajski (Ed.) Western Balkans Policy Review 2010 Washington, DC: Center for Strategic and International Studies, pp. 34-44.

Galgóczi, Béla and Bruno S. Sergi (2012) Social and economic trends in south-east Europe Brussels: European Trade Union Institute.

Meyer C. E and W. L. Nash (2002) Balkans 2010 Council on Foreign Relations: New York.

Ndulo, M. B and R. Duthie (2009) 'The Role of Judicial Reform in Development and Transitional Justice' in: P. D. Greiff and R. Duthie (Eds.) Transitional Justice and Development: Making Connections Social Science Research Council: New York, pp. 250-281.

Qerimi, Qerim and Bruno S. Sergi (2005) 'On the relevance of the EU as a means of spurring a socially-sustainable south-east Europe' South-East Europe Review for Labour and Social Affairs 8(3): 111-120.

Qerimi, Qerim and Bruno S. Sergi (2009) 'The global financial crisis and the postLisbon prospects of enlargement' South-East Europe Review for Labour and Social Affairs 12(4): 439-460.

Qerimi, Qerim and Bruno S. Sergi (2012) 'Unemployment and the Eurozone crisis: the state of social welfare in the Balkans' South-East Europe Review for Labour and Social Affairs 15(4): 425-431.

Sergi, Bruno S (2004) 'Understanding the EU factor: the Balkan region as recipient of FDI and industries' South-East Europe Review for Labour and Social Affairs 7(4): 7-20.

Sergi, B. S and Q. Qerimi (2007) 'Fighting corruption and organised crime as a means of socio-economic development in south-east Europe' South-East Europe Review for Labour and Social Affairs 10(2): 81-94.

Sergi, B. S and Q. Qerimi (2008) The Political Economy of Southeast Europe from 1990 to the Present New York: Continuum. 